\title{
Design and Application of Liquid Chromatography Dual Electrode Detection
}

\author{
Kevin C. Honeychurch \\ Centre for Research in Analytical, Materials and Sensors Science, Faculty of Applied Sciences, \\ University of the West of England, Bristol, Frenchay Campus, Coldharbour Lane, Bristol, BS16 1QY, \\ $U K$. \\ Corresponding Author Tel. +44 (0)117 3282490, Fax. +44 (0)117 3282904, email \\ kevin.honeychurch@uwe.ac.uk
}

\section{Abstract}

This review describes developments in the design and application of liquid chromatography dual electrode detection. The design and relative merits of both series and parallel electrode systems are examined. The application of liquid chromatography dual electrode detection for environmental, pharmaceutical, biomedical analysis is discussed. Specific emphasis is placed on operating details and performance characteristics for selected architectures and applications.

\section{Introduction}

Liquid chromatography with electrochemical detection has been shown to be both highly sensitive and selective. Initially electrochemical detection in this approach has utilised single electrode based electrochemical detector systems, where the compounds eluting form the chromatographic are detected by direct oxidation or reduction to generate the analytical signal. This has been shown to work well for a range of compounds. However, a number of analytes require high applied potentials for their oxidation or reduction. This can lead to problems in decreased signal-tonoise ratios, increased interference problems and large background currents. Several methods to overcome these issues have been investigated, such as derivatisation which can add further complexation to method and the possible introduction of 
contaminates that can interfere. An alternative approach is the application of dual electrode detection. In this approach two electrodes can be arrange either in series or parallel after the liquid chromatographic analytical column. This offers a number of advantages as the complexity of the method can be reduced and both sensitivity and selectivity can be improved.

This review describes the design and application of liquid chromatography dual electrode detection. The first section discusses the design of this detector system, highlighting some of the different detector systems and configurations, such as parallel and series detectors. In the second section, a number of different example applications are described for environmental, pharmacology and industrial areas.

\section{High Performance Liquid Chromatography}

High-performance liquid chromatography (HPLC) has been shown to be an extremely powerful technique. A large number of compounds have been shown to be amenable to separation by this procedure, with the main governing factor being only their degree of solubility in a suitable mobile phase. HPLC was originally developed from liquid chromatography (LC) which has been used for long time as a method of separation. For LC, an absorbent (alumina or silica) is packed into a column, and the sample introduced at the top. The sample is then eluted with a suitable solvent commonly under gravity or a vacuum. If the sample (solute) is weakly adsorbed on to the surface of the column it will travel faster than those strongly adsorbed, hence separation arises. LC commonly uses glass columns $(5 \mathrm{~cm}$ internal diameter, and a 1 $\mathrm{m}$ long). Long columns are needed for tricky separations, which lead to long analysis times and large amounts of solvents. The solutes eluted are divided up into fractions by collecting measured volumes eluted from the column. These can then be 
determined by some over off-line method. The technique is not very efficient; however, it is very good for preparative work.

\subsection{Basics of High Performance Liquid Chromatography}

As the name implies, is a much more efficient version of LC. Chromatography efficiency can be improved by the reduction of the particle size of the stationary phase. Columns with particle sizes of around $5 \mu \mathrm{m}$ came into use the 1960s, which saw the rise in interest in HPLC. These particles are formed from porous silica spherical or irregular in shape, to which different organic phases are added by derivatisation of the $\mathrm{SiOH}$ groups present on the surface of the particles to form bonded phases. These columns are $5-30 \mathrm{~cm}$ in length with an inner diameter of $1-$ $5 \mathrm{~mm} ; 4.6 \mathrm{~mm}$ being common. The vast majority of HPLC work (ca. $75 \%)$ is presently undertaken using bond phases consisting of $\mathrm{C}_{18}$ (octadecyclsilane, ODS); this is however an area of change. Commonly these stationary phases provide 50,000 to 10,000 plates $/ \mathrm{m}$.

The small particle size is important as if the solute can diffuse rapidly between the mobile phase and stationary phase then plate height is improved and resolution also increases. In HPLC the rate of mass transfer between the mobile phase and the stationary phase is increased by reducing the dimensions of the stationary phase particles, consequently reducing the distance through which the solute must diffuse in both phases. Smaller particles also make migration paths more uniform. However, the penalty for using very small particles is resistance to solvent flow. Pressure of 7 $40 \mathrm{MPa}$ (approximately $70-400 \mathrm{Bar}$ ) are routinely required to attain flow rates of 0.5 $-5 \mathrm{~mL} / \mathrm{min}$.

These high pressures utilised routinely in HPLC require something that can exert a greater force than that can be produced by gravity or vacuum to produce a continuous 
flow of mobile phase through the analytical column. Consequently, modern HPLC systems commonly utilise pulse free, continuous flow pumps capable of operating at these pressures and suitable Rheodyne type injectors that allow for sample introduction into pressurised systems [1].

\subsection{Common Modes of Liquid Chromatographic Separation}

\subsubsection{Normal and Reverse Phase}

In normal phase chromatography the stationary phase (the column) is relatively polar and the mobile phase is non-polar (i.e. hexane and chloroform). This is not generally utilised in modern analytical applications as only small changes in the mobile phase composition and the presence of small amounts of water can lead to marked changes in the retention times of the target analytes. The use of large amounts of potentially volatile, toxic solvents has also made it less attractive and measures have to be taken to avoid evaporation of the mobile phase. Normal phase HPLC is also less attractive for application with electrochemical detector systems as it can be difficult to incorporate a suitable supporting electrolyte or buffer.

Reverse phase chromatography, as the name suggests can be thought as the opposite of normal phase, generally using a non-polar stationary phase (hydrocarbon, $\mathrm{C}_{18}$ or similar), with a polar mobile phase (acetonitrile, methanol, tetrahydrofuran and water). The vast majority of modern HPLC applications utilise this approach; it avoiding the issues associated with normal phase. The separation of target analytes can be readily controlled by modification of the percentage solvent used in the mobile phase and use of common buffers such as acetate and phosphate. When buffers are used they are normally low to moderate ionic strengths; in the region of 0.010 to 0.1 $\mathrm{M}$ to control the speciation of the target analyte and in electrochemical detection provide conductivity, while avoiding contribution to the background current. Trace 
impurities found in mobile phases are notably a problem especially when reductive mode electrochemical detection is utilised where trace concentrations of metal ions and oxygen can cause significant problems. The removal of oxygen can be achieved by purging of the mobile phase with nitrogen or similar inert gas. However, it can be problematic to achieve similar with sample extracts and to avoid the diffusion of oxygen back into the HPLC system via tubing and solvent reservoirs.

\subsubsection{Hydrophilic Interaction Liquid Chromatography}

The analysis of some compounds such as amines by reverse phase HPLC can lead to problems due to their hydrophilic nature leading to low retention; necessitating the application of ion pairing agents [2], buffers, or low concentrations of organic modifiers [3] which can lead to stationary phase de-wetting. The presence of ionised silanol groups on the stationary phase can also result in peak tailing and overloading resulting in poor separation and analytical performance [4,5]. To address these issues, approaches such as hydrophilic interaction liquid chromatography (HILIC) have been developed [6,7]. HILIC is becoming an established alternative technique to overcome these issues [8,9]. HILIC is often thought as being an orthogonal approach to reverse phase HPLC, allowing for compounds with poor retention under reverse phase HPLC to be retained and separated. The exact mechanism is still an area of research, but a simple explanation would show that under HILIC conditions a thin layer of water is formed at the surface of a polar stationary phase and analytes partition between this and a solvent rich mobile phase (commonly $70 \%$ to $95 \%$ acetonitrile) and so achieve chromatographic separation. As with normal phase chromatography, high percentages of organic modifier, principally acetonitrile, can lead to issues with electrochemical detection, as the application of a suitable buffer or supporting electrolyte can be problematic. However, recently the application of HILIC has been 
shown to be readily attainable with liquid chromatography with dual electrode detection [9].

\section{Electrochemical Detectors}

Competing techniques such as gas chromatography (GC) are generally more selective due to the wider range of detectors that are generally available. However, samples for GC need to be volatile and thermal stable, meaning that only about $20 \%$ of compounds are suitable for GC assay without a prior preparation step. Certain compounds such as those with polar groups often give poor chromatography via GC (i.e. tailing peaks in the case carboxylic acids). For HPLC sample compounds only need to be soluble in a suitable mobile phase, which means a much larger sample range can be analysed. Liquid chromatographic separations are also commonly undertaken at or close to room temperature, avoiding issues of thermal degradation of the target analytes.

HPLC detectors have been limited to those which utilise the absorption of light in some way or to electrochemistry. In more recent years the use of mass spectrometry based detector systems has greatly expanded the range of compounds that can be determined. However, this is rather expensive and sophisticated requiring highly trained staff for its operation. Recently, Trojanowicza has reviewed the utilisation of electrochemical detection with both flow injection analysis [10] and liquid chromatography [11] for a range of compounds and several reviews have been made on the underlying theory [12-15]. Attention first focused on liquid chromatography electrochemical detection (LC-ED) with regard the determination of dopamine and other related neurotransmitters, leading to the first commercially available detectors being produced in 1974 [15]. Successful adaptation have been made to this approach using pulse waveforms [16] and electrode materials and geometries. 


\subsection{Amperometric and Coulometric Detectors}

Initially, amperometric detection had been the most widely used detection approach for applications involving the trace analysis of organic components in complex biological and environmental media. Attempts to optimise amperometric detector design have resulted in the development of principally three different detector designs: the tubular electrode [17], the wall-jet electrode [18], and the most commercially successful the thin-layer cell [19]. A detailed description of these cell types has been given [1].

\subsection{Thin-Layer Cell}

The thin-layer cell is properly the most common and commercially successfully amperometric detector cell. These have been constructed in number of ways, utilising differing materials, but are characterised by a fluid flow that is contained parallel to the working electrode (normally $2-4 \mathrm{~mm}$ diameter) imbedded in a rectangular channel or by directing the stream perpendicular to the surface followed by radial dispersion. A variety of working electrode materials have been investigated, including most of the commonly employed working electrode materials; platinum, gold and carbon. The electrochemical active compound is flowed over the electrode held at a potential sufficiently greater than the potential required for electron transfer to occur. An amperometric current is produced; proportional to the concentration of the analyte that has entered the cell. The concentration of the analyte changes with time due to its elution from the chromatographic column. As a result the amperometric current formed increases and decreases with time as the eluting compound travels through the cell. This results in a peak shaped response if time (xaxis) and current are plotted ( $y$-axis), giving the classical chromatogram.

\subsection{Wall-Jet Design}


One amperometric detector which has been reported to improve responses is the walljet design. This is a modification of the thin-layer electrode. In this configuration eluent for the HPLC system column is directed perpendicularly to the plane of a thinlayer working electrode [20]. The theory behind this design states that as eluent from the HPLC column is directed at the working electrode surface head on, mass transfer of analyte to the surface of the electrode is improved, resulting in greater current amplitudes. However, under the common flow rates utilised in HPLC separation $(0.5$ $\mathrm{mL} / \mathrm{min}$ to $2 \mathrm{~mL} / \mathrm{min}$ ) the true wall-jet effect will not occur and this configuration may only give small improves in sensitivity.

\section{Dual Electrodes Detection Systems}

One such technique that has been shown to both improve the selectivity and sensitivity is that of the dual electrode electrochemical detection (DED). There are two different types of dual electrode detector systems: in series, or in parallel. Further modification of these terms is gained by the application of either amperometric or coulometric electrodes.

\subsection{In Series Configuration}

This configuration uses the two working electrodes in the flow channel which can be independently potentiostatically controlled. This has been liken to the fluorescence detector, as the product of the upstream electrode reaction is detected at the downstream working electrode. Figure 1 shows a summary of the various architectures. The first working electrode $\left(\mathrm{W}_{1}\right)$ can be used as what is generally referred to as the "generator", with the second working electrode $\left(\mathrm{W}_{2}\right)$, as a “detector". The generator electrode creates, through either reduction or oxidation an electrochemical active adduct, which can then be measured at the second detector electrode. Generally, the advantage of this approach is twofold; firstly, the 
electrochemical adduct has a much improved electrochemical properties, it being much more easily oxidised or reduced than the parent compound. This hence necessitates less harsh electrochemical conditions for its detection. Secondly, a number of other compounds present in the sample extract which could possible interfere can be irreversibly reduced or oxidise at the downstream generator electrode, and hence will not be seen at the upstream detector cell. Due to the relatively low potentials that can be employed, background currents at the detector electrode are generally much lower than that seen at the high potentials required for direct electrochemical detection.

This improvement can be readily seen when compared to single electrode detection shown in Figure 2 [21]. Here the determination of $p$-nitrophenol (PNP) has been undertaken in human urine extracts by both dual electrode detection and single oxidative mode detection. The oxidative mode detection trace is characterised by large number of co-eluting peaks which obscure the retention time expected for PNP. However, by DED a relative clean trace is recorded. The presence of PNP in the fortified urine extract can be readily recorded. 

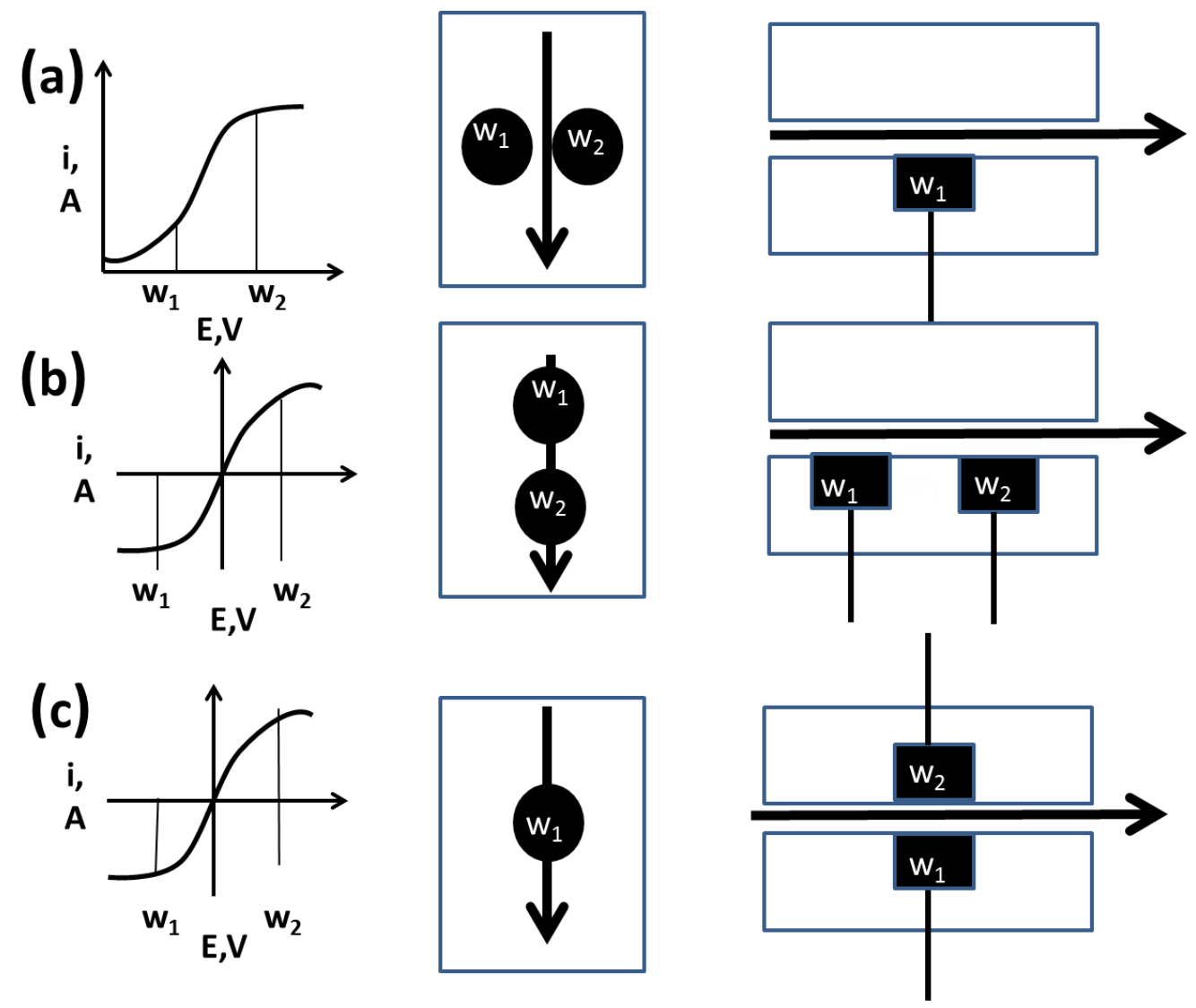

Figure 1. Parallel and series configurations for dual electrode detection systems. $\mathrm{W}_{1}$ = working electrode $1 ; \mathrm{W}_{2}=$ working electrode 2 . (a) parallel; (b) series and (c) parallel adjacent. Arrow indicates direction of flow. 


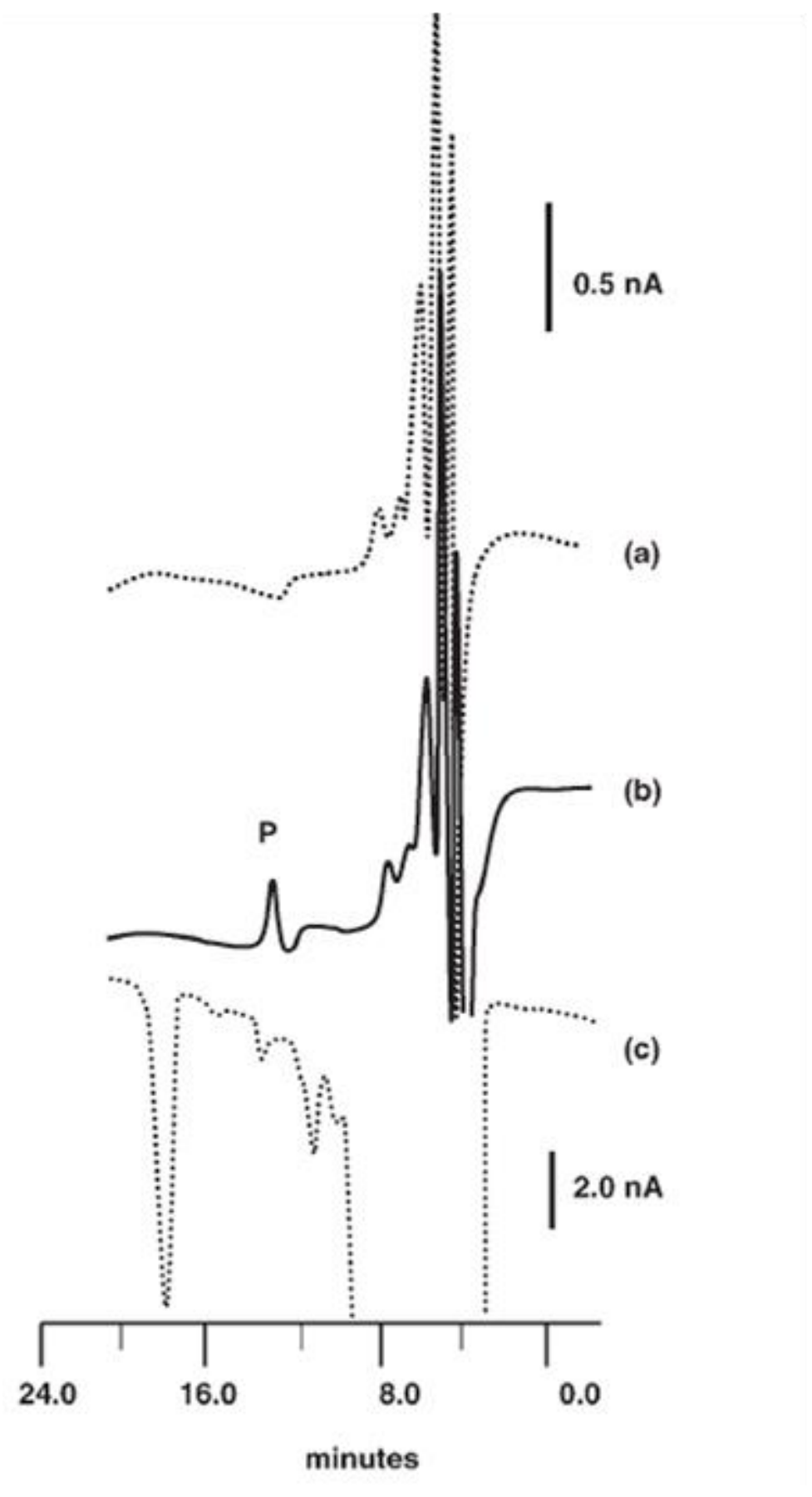

Figure 2. Representative chromatograms of PNP $(\mathrm{RT}=13.6 \mathrm{~min})$ for a) and c) unfortified human urine, and b) fortified at $522 \mathrm{ng} / \mathrm{mL}$; (a) and (b) obtained for LC$\mathrm{DED}$, (c) by LC with single oxidation detection at p1.0 V. $(\mathrm{P}=\mathrm{PNP})$. Flow rate 0.5 mL/min. K.C. Honeychurch, J.P. Hart, Electroanalysis, 2007, 19, 2176-2184 [21]. 


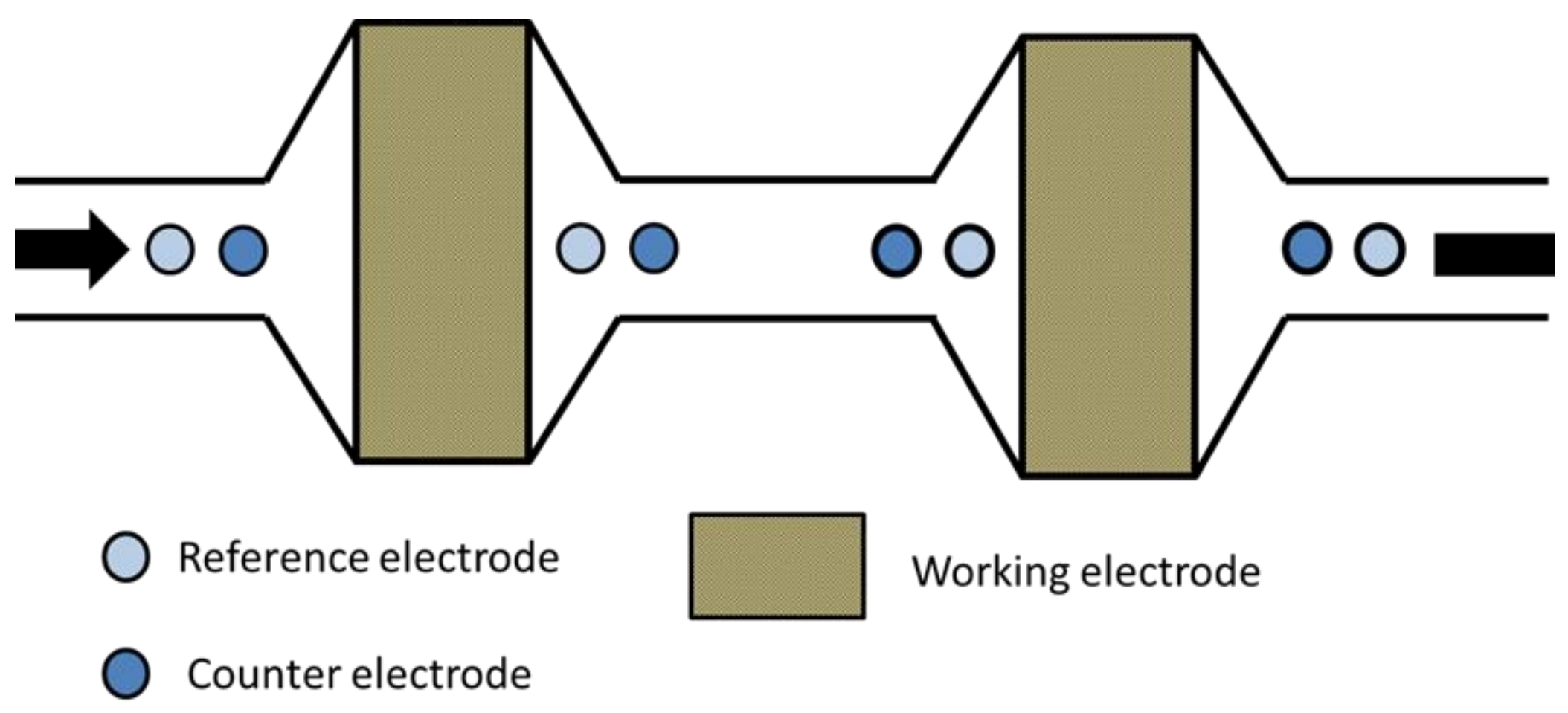

Figure 3. Cross section through a dual coulometric electrode showing the placement of working, counter and reference electrodes 
However, when using amperometric cells such as the TLC in the series mode only a small percentage of the compounds passing through the downstream generator cell will be electrochemically oxidised or reduced. The same is true for the second upstream amperometric electrode which will in turn convert only a fraction of the products generated by the first electrode, which represents only fraction of the total analyte entering the cell.

When two separate cells are used, the collection efficiency is simply equal to the conversion efficiency of the second electrode. Therefore, with separate cells the first cell should have a high conversion efficiency. For the downstream cell the same arguments on sensitivity are valid as for single electrode detection.

A different situation arises when the two working electrodes are placed in the same thin-layer cell compartment together. The collection efficiency in such will be higher than separate TLCs, since the products of the first upstream electrode are concentrated on the electrode side of the TLC compartment, and diffusion takes place over a shorter distance normal to the electrodes.

\subsection{Parallel Dual Electrode Detection}

\subsubsection{Parallel Dual Electrode Configurations}

In the parallel mode (figure $1 \mathrm{~b}$ ) as the name suggests, two identical electrodes are arranged side-by-side after the analytical LC column, so that the eluent contacts them both concurrently. The advantage of this approach is that it is possible to hold the two electrodes at different potentials points along the hydrodynamic wave of the target analyte. The ratio of these two currents can then be measured and used to confirm the identity and peak purity of the eluting compound when compared against a known analytical standard. Further to this, it is possible to use the parallel detector in a different mode, to measure both oxidisable and reducible species simultaneously, by 
applying different potential to each electrode. By setting one electrode at a positive potential and the other at a negative potential Lute and Kissinger [22] have used this approach for the determination of pterins, which occur in tissues in both their oxidised and reduced forms. Co-eluting compounds with different redox potentials can be determined by selecting the potential of one electrode so that only the more easily oxidised (or reduced) compound is detected, while at the other parallel electrode both compounds are electrochemically detected. The concentration of the second compound can hence be calculated by difference

Figure 1c shows a further alternative configuration, the parallel opposed detector. This detector was first reported in the late 1960s by Anderson and Reilley [23]. The configuration of this detector allows for the cascade of reversible redox reactions in order to amplify the detector current and reportedly values as high as tenfold have been reported [24,25]. In this configuration the working electrodes are on opposite sides of a very thin channel, with one electrode at an oxidative potential and one at a reducing potential. When the spacer is thick, then the two electrodes can act as independent parallel dual electrodes, but with a thin spacer products of one electrode can diffuse to other and vice versa. When the electrodes are sufficiently large, each analyte particle can pass through a number of oxidation-reduction cycles, so that the conversion efficiency of the cell can be much larger than one. Fenn et al. [26] have used this approach for the determination catecholamines in blood plasma at flow rates of less than $0.2 \mathrm{~mL} / \mathrm{min}$. However, signal to noise ratios are not improved. Signals are amplified compared to a cell with only one working electrode of the same dimensions, but the amplification effect only diminishes the decrease of sensitivity compared to a small-electrode cell. Current amplification may be used as an alternative for series dual electrode detection, with the advantage that oxidisable and 
reducible compounds can be detected simultaneously. Due to the relatively long residence times in cell, it discriminates especially against interfering compounds which undergo irreversible homogenous side reactions.

\subsection{Coulometric Detectors}

As mentioned in the previous section, commonly for amperometric detectors the efficiency for the conversion of the target analyte is often around only 1-10\%. This value is dependent on the mass transport efficiency of the cell; related to electrode area, channel thickness and the flow rate. However, to achieve high efficiencies with a thin-layer cell is generally difficult when used in conjunction with HPLC, as either the cell volume would be extremely small, leading to high back pressure issues, or the flow rate incompatible with good chromatographic performance.

Alternatively, a coulometric detectors can be employed which generally utilise flowthrough electrodes. A number of different designs and working electrode materials have been investigated [27]. However, generally commonly used commercial detectors use porous carbon electrodes with high surface areas and reduced diffusion distances giving close to $100 \%$ (coulometric) efficiency and high sensitivity (figure $3)$.

As a result of the high coulometric efficiencies that can be gained the series configuration can be used in the "screening" mode, here the first upstream electrode is used to remove possible interfering compounds as they elute from the analytical LC column. By careful selection of this potential, the target analytes then pass through, and measured at the downstream "detector" electrode, but now in the absence of a number of the possible interferences present in the sample. A variation of this concept has led to the development of detectors consisting of up to sixteen coulometric detectors in series, to form a coulometric array; the application of which 
has been extensively reviewed [27-30] and is hence not covered in this chapter. The same design can be successfully employed in the generator/detector mode. This can be seen to have a number of advantages over the dual amperometric system resulting from the high conversation rates that can be obtained at each electrode. These advantages have resulted in properly the commercially most successful detector system originally manufactured by ESA as the Coulochem detector. The series dual electrode detector is available with either dual coulometric electrodes or with a coulometric generator and an amperometric detector electrode.

\section{Applications}

There have been numerous reports on its usage in a wide field of applications. It is difficult to adequately identify reports from their title and abstracts that utilised LC DED as this is not always explicitly stated. However, it is possible to generalise by giving an overview of the classes of compounds reported. The most frequently reported are: nitro-aromatics, hydroquinones, catecholamines, thiols and amines.

\subsection{Catechol Containing Structures}

The catechol (1,2-dihroxybenzene) group is one of the most commonly electrochemically studied compounds. Neurotransmitters, such as; dopamine, adrenaline, noradrenaline and a number of their oxidation products are readily undergo reversible electrochemically redox behaviour at low applied potentials via a two electron step with their corresponding orthoquinone. However, these compounds generally offer poor chromatography when using reverse phase stationary phases. One way of improving the chromatography of catechol compounds is the use of ionpair reagent. Commonly, reagents such as sodium octadecylsulphate (ODS) or sodium heptane sulphonate are reported and used in low concentrations in the mobile phase, between 1 and $20 \mathrm{mM}$. The acid functional groups of these compounds endow 
the stationary phase of the reverse phase column with the characteristics of a cationexchange column, improving the retention of these compounds. Goto [31] has reported on the determination of number of catecholamines, including: 3,4dihydroxyphenylacetic acid (i), homovanillic acid (ii), and 5-hydroxyindole-3-acetic acid using a mobile phase of $\mathrm{pH} 3.6$ Britton Robinson buffer, containing $10 \%$ methanol, $50 \mathrm{mM}$ sodium perchlorate and $0.1 \mathrm{M}$ EDTA using a series configuration dual electrode system. The upstream and downstream electrodes were set to $+0.8 \mathrm{~V}$ and $-0.05 \mathrm{~V}$ respectively.<smiles>O=C(O)Cc1ccc(O)c(O)c1</smiles>

(i)<smiles>COc1cc(CC(=O)O)ccc1O</smiles>

(ii)<smiles>O=C(O)Cc1c[nH]c2ccc(O)cc12</smiles>

(iii) 


\subsection{Drugs and Pharmaceuticals}

\subsubsection{Nitroaromatic Compounds}

By using an in series-LC-DED in the redox mode, it is possible to electrochemically reduce aromatic nitro compounds to their corresponding hydroxylamine. This species can then be readily measured at the subsequent downstream "detector" electrode via oxidation to the nitroso. This is attractive analytically; this latter species can be measured at potentials close to that of $0 \mathrm{~V}$, away from many possible interfering compounds. This approach has been used by us for the determination of nitro aromatic drug, nitrazepam (iv) in bovine and human serum [32].

In this investigation, the electrochemical mechanism occurring at a glassy carbon electrode was first investigated by cyclic voltammetry using $1 \mathrm{mM}$ solutions of nitrazepam at $\mathrm{pH}$ values between 2 and 12; using a potential range from $-1.5 \mathrm{~V}$ to $+1.5 \mathrm{~V}$. Two reduction peaks were observed over the whole $\mathrm{pH}$ range; the first was consistent with the $4 \mathrm{e}^{-}, 4 \mathrm{H}^{+}$reduction of the 7-nitro group to a hydroxylamine species; the second more negative peak was shown to be the result of a $2 \mathrm{e}^{-}, 2 \mathrm{H}^{+}$reduction of the 4-5 azomethine group. On the reverse anodic scan, an oxidation signal was observed which was considered to result from a $2 \mathrm{e}^{-}, 2 \mathrm{H}^{+}$oxidation of the hydroxylamine to a nitroso group. On the second forward scan a new reduction peak was observed which was considered to result from reduction of the nitroso species back to the hydroxylamine species. Studies were then undertaken to exploit the hydroxylamine/nitroso redox couple using LC-DED for the detection of nitrazepam at two home-made amperometric thin-layer cells, each containing $3 \mathrm{~mm}$ diameter glassy carbon working electrodes. The optimal chromatographic conditions were found to comprise a mobile phase containing $60 \%$ methanol, $40 \% 50 \mathrm{mM} \mathrm{pH} 4.1$ acetate buffer, in conjunction with a Hypersil $\mathrm{C}_{18} 250 \mathrm{~mm}$ x $4.6 \mathrm{~mm}$ column. Hydrodynamic 
voltammetric studies were undertaken to optimise the operating potentials required for dual electrode detection. It was found that an applied potential of $-2.4 \mathrm{~V}$ (vs. stainless steel pseudo-reference counter electrode) was optimum for the "generator" cell and $+0.5 \mathrm{~V}$ (vs. $\mathrm{Ag} / \mathrm{AgCl}$ ) for the "detector" cell. A simple and rapid sample preparation step was employed, requiring only simple addition of acetone to serum, followed by filtration. Recoveries for bovine serum were reported to be $75.8 \%$ and the associated coefficient of variation was $6.1 \%(n=6)$. For human serum the recovery was $74.1 \%$ with a coefficient of variation of $7.8 \%(n=7)$.

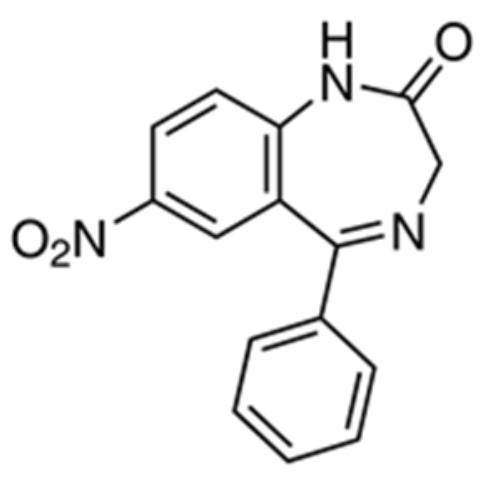

(iv)<smiles>O=C1Nc2ccc(Cl)cc2C(c2ccccc2Cl)=NC1O</smiles>

(vi)<smiles>CN1C(=O)CN=C(c2ccccc2F)c2cc([N+](=O)[O-])ccc21</smiles>

(v)<smiles>CN1C(=O)CN=C(c2ccccc2)c2cc(Cl)ccc21</smiles>

(vii) 
A variation of this approach has been reported for the determination of nitrazepam (iv), and flunitrazepam (v) in beverages [33]. A carbon fibre veil electrode was incorporated was utilised as the generator electrode. A novel reduction-reduction LCDED approach was exploited to determine the two drugs. The initial reduction reaction occurring at the at the amperometric generator electrode was believe to occur via a two $2 \mathrm{e}^{-}, 2 \mathrm{H}^{+}$reduction of the 7-nitro group to its corresponding nitroso species. A further $2 \mathrm{e}^{-}, 2 \mathrm{H}^{+}$reduction then postulated to occur at the downstream amperometric detector electrode to give the corresponding hydroxylamine. Using this method a linear range of 2.0 to $100 \mu \mathrm{g} / \mathrm{mL}$, with a detection limit of $20 \mathrm{ng} / \mathrm{mL}$ was found. Following a simple solvent extraction, a mean recovery of $95.5 \%(\% \mathrm{CV}=4.5 \%)$ for nitrazepam and 78.0\% (\%CV $=8.8 \%)$ was achieved for a sample of Pepsi Max® spiked at $1.0 \mu \mathrm{g} / \mathrm{ml}$ nitrazepam (iv) and $1.47 \mu \mathrm{g} / \mathrm{ml}$ flunitrazepam (v).

Honeychurch et al. [34] have shown it possible to determine flunitrazepam (v), lorazepam (vi) and diazepam (vii) in serum by LC-DED in the redox mode. Studies were performed to optimise the chromatographic conditions and were found to be 50 $\%$ acetone, $50 \% 100 \mathrm{mM} \mathrm{pH} 2$ phosphate buffer at a flow rate of $0.8 \mathrm{ml} / \mathrm{min}$, employing a Hypersil C18, $5 \mu \mathrm{m}, 250 \mathrm{~mm}$ x $4.6 \mathrm{~mm}$ column held at $40{ }^{\circ} \mathrm{C}$ using a generator potential of $-2.4 \mathrm{~V}(v s$. stainless steel) and detector potential of $+1.0 \mathrm{~V}$ ( $v s$. $\mathrm{Ag} / \mathrm{AgCl}$ ). Enhancement in both peak height and peak area (coulombs) was seen with decreasing flow rate, probably resulting from improvements in the electrolytic conversion efficiency of the cell at lower flow rates. This decrease in flow rate results in a higher conversion of the analyte at the working electrode and consequently, larger peak areas (coulombs) are expected.

A number of common azo based dyes are known to be possible carcinogens. This results from their metabolism to more labile products in the liver. Analysis of these 
metabolites is obviously an important in a number of areas. Radzik et al [35] have utilised LC-DED in both in the redox mode and in parallel for the determination the metabolites of Disperse Orange 3 (viii) liver microsomal fractions. No prior extraction, pre-concentration or derivatisation was required for the analysis of the principle metabolites: 4-nitroaniline (ix), 2-amino-5-nitrophenol (x) and N-hydroxy-4nitroaniline (xi) in the sub-pM range.

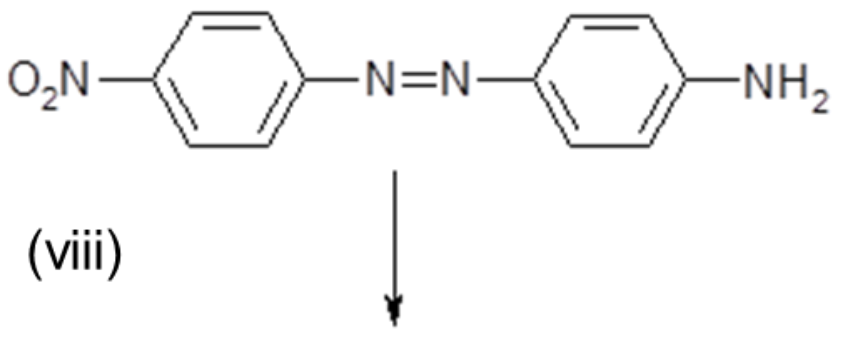

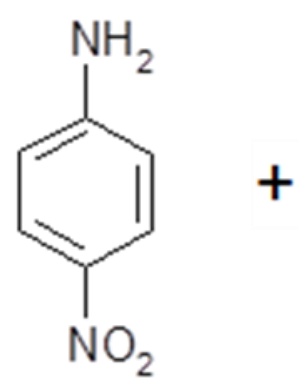

(ix)<smiles>Nc1ccc([N+](=O)[O-])cc1O</smiles>

$(\mathrm{x})$<smiles>O=[N+]([O-])c1ccc(NO)cc1</smiles>

(xi)

Cyclic voltammetric investigations demonstrated that the three compounds be readily reduced to form products with oxidation products close to $0 \mathrm{~V}$. LC-DED, using a "generator" cell potential of $-0.65 \mathrm{~V}$ and a "detector" cell potential of $+0.7 \mathrm{~V}$ were shown to be give detection limits for all three compounds at least twice as low as that reported for reductive detection at $-0.65 \mathrm{~V}$, principally as result of the much improved signal-to-noise ratios seen with LC-DED. The target analytes were successfully resolved from other sample components using a mobile phase of $8.0 \%$ n-propyl 
alcohol and $92 \% 0.1 \mathrm{M}$ monochloroacetic acid, pH 3.0 containing $3.6 \mathrm{mM}$ triethylamine.

\subsection{Environmental Exposure}

Rogers et al. [36,37] have undertaken two related studies on the LC-DED determination of a number of phenols; in the second most recent report of this [37] they have used a LC-DED in the series mode for the determination of a number of phenols, including; catechol (xii), phenol (xiii), $p$-cresol (xiv), $p$-chlorophenol (xv), $p$ acetamidophenol (xvi) and $p$-nitrophenol (xvii). The upstream carbon-paste electrode was held at $+1.0 \mathrm{~V}$ was used to screen the column eluent before detection of the phenol analytes at the second downstream tyrosinase modified carbon paste electrode. The enzyme tyrosinase (polyphenoloxidase; EC 1.14.18.1) is involved in the phenomenon of browning of fruits and is present in mushrooms, apples and potatoes, catalyzing phenol oxidation with molecular oxygen through two distinct reactions: through the ortho-hydroxylation of phenol producing catechols and its dehydrogenation to give quinones. These enzymatically generated quinones can then be electrochemically detected at $-0.2 \mathrm{~V}$ at the same downstream electrode. The overall enzymatic/electrochemical process is shown in figure 4A. Enzyme oxidation followed by reduction at the electrode results in cycling between the electrochemically generated catechol, and the enzymatically generated quinone resulting in a catalytically amplified current. The signal amplification through this type of cycling of the quinone product has been shown to increase the sensitivity of the assay by about 70 times, with linear ranges in the region of 0 to $100 \mu \mathrm{M}$ being reported in this study. Investigations were made to ascertain the optimum binder and percentage used in the carbon-paste, and tyrosinase carbon paste electrodes prepared by $60 \mathrm{mg}$ graphite powder with $40 \mathrm{mg}$ of silicon oil binder Si PS 086, with $3 \mathrm{mg}$ of 
tyrosinase enzyme ( $3 \% \mathrm{w} / \mathrm{w})$ mixed with $97 \mathrm{mg}$ carbon paste, were found to be optimal.<smiles>Oc1ccccc1O</smiles>

(xii)<smiles>Oc1ccccc1</smiles>

(xiii)<smiles>Cc1ccc(O)cc1</smiles>

(xiv)<smiles>Oc1ccc(Cl)cc1</smiles>

(xv)<smiles>CC(=O)Nc1ccc(O)cc1</smiles>

(xvi)<smiles>O=[N+]([O-])c1ccc(O)cc1</smiles>

(xvii)

A

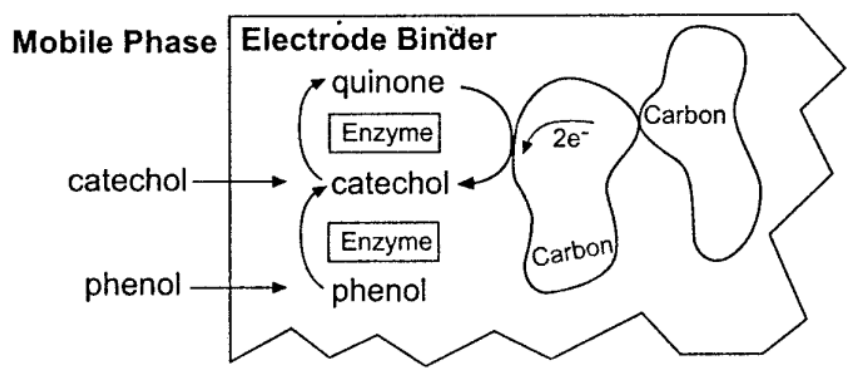

B

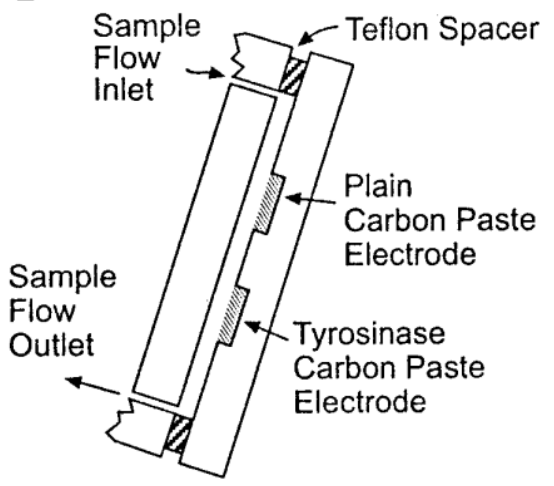

Figure 4. Diagrammatic representation of the enzyme electrode (A) and thin layer chromatographic cell (B). K.R. Rogers, J.Y. Becker, J. Cembrano, Electrochim. Acta, 2000, 45, 4373-4379 [37].

The determination of trace $p$-nitrophenol (PNP) (xvii) concentrations in human urine has been successfully achieved by high performance liquid chromatography dual electrode detection (LC-DED) in the reduction-reduction mode [21]. Initial cyclic 
voltammetric studies were undertaken to investigate the electrochemical behaviour of PNP at a glassy carbon electrode over a wide $\mathrm{pH}$ range; the redox processes giving rise to the signals have been deduced. Further, deductions regarding the behaviour in the flow cells were made from hydrodynamic voltammetric data. PNP eluting from the analytical LC column is first reduced to $p$-hydroxylaminophenol, at the first generator electrochemical cell. This species then undergoes chemical oxidation to give a quinoneimine species which is then detected at the downstream detector electrode using an applied potential of $-0.1 \mathrm{~V}$. The optimum chromatographic mobile phase consisted of $40 \%$ acetonitrile, $60 \%$ water, containing $25 \mathrm{mM}$ o-phosphoric acid, at a flow rate of $0.5 \mathrm{ml} / \mathrm{min}$; this was used in conjunction with a Hypersil $\mathrm{C}_{18}$ column. Hydrodynamic voltammetric studies were undertaken to investigate the dual electrode behaviour of PNP, and an applied potential of $-2.0 \mathrm{~V}$ at the generator cell and $-0.10 \mathrm{~V}$ at the detector cell were found to be optimum. The response was found to be linear over the range $7.0 \mathrm{ng}$ to $500 \mathrm{ng}$ on column, with an associated $\mathrm{R}^{2}$ value of 0.9981; the limit of detection was found to be $1.0 \mathrm{ng}$ PNP on column. No interferences were seen for a number of common drugs or for the principal electrochemically active components of human urine or serum. The developed assay was successfully applied to the determination of trace concentrations of PNP in human urine samples, exhibiting coefficients of variation of $7.1 \%(n=7)$, with a mean recovery of $94.7 \%$ for urine fortified at $522 \mathrm{ng} / \mathrm{ml}$.

\subsection{Biomedical}

Ohshima et al. [38] have determined 3-nitrotyrosine (xviii), at a $250 \times 4.6 \mathrm{~mm}, 5 \mu \mathrm{m}$ ODS column using isocratic conditions with $10 \mathrm{mM}$ aqueous $\mathrm{NaH}_{2} \mathrm{PO}_{4}$ containing 10 $\%$ methanol. A guard cell sited before the analytical column, held at $+1.1 \mathrm{~V}$ (Coulochem II). Compounds eluting form the analytical column were then reduced at 
a stainless steel "generator" column $(10 \mathrm{~mm}$ x $4.6 \mathrm{~mm})$ packed with platinum-black powder; type RC-10-1 at an applied potential of $-1.0 \mathrm{~V}$. This was connected in series to a conditioning cell, again held at $-1.0 \mathrm{~V}$, before subsequent detection at a parallel dual electrode cell, at $+0.9 \mathrm{~V}$ and $+1.0 \mathrm{~V}$.

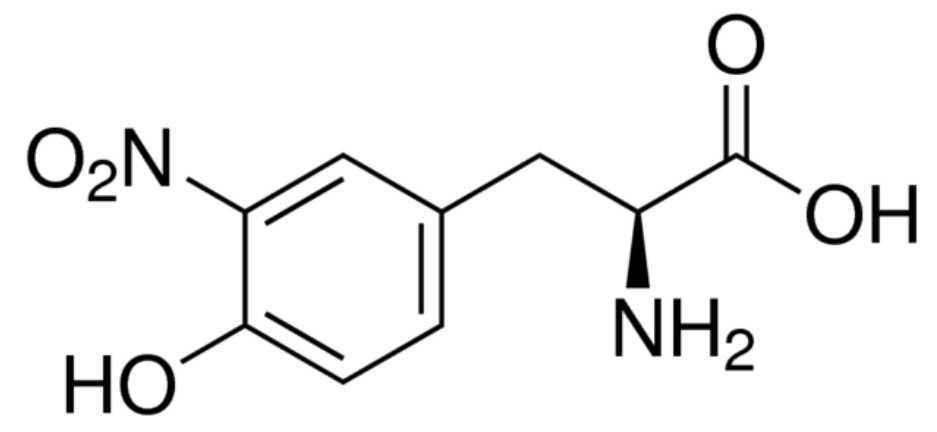

(xviii)
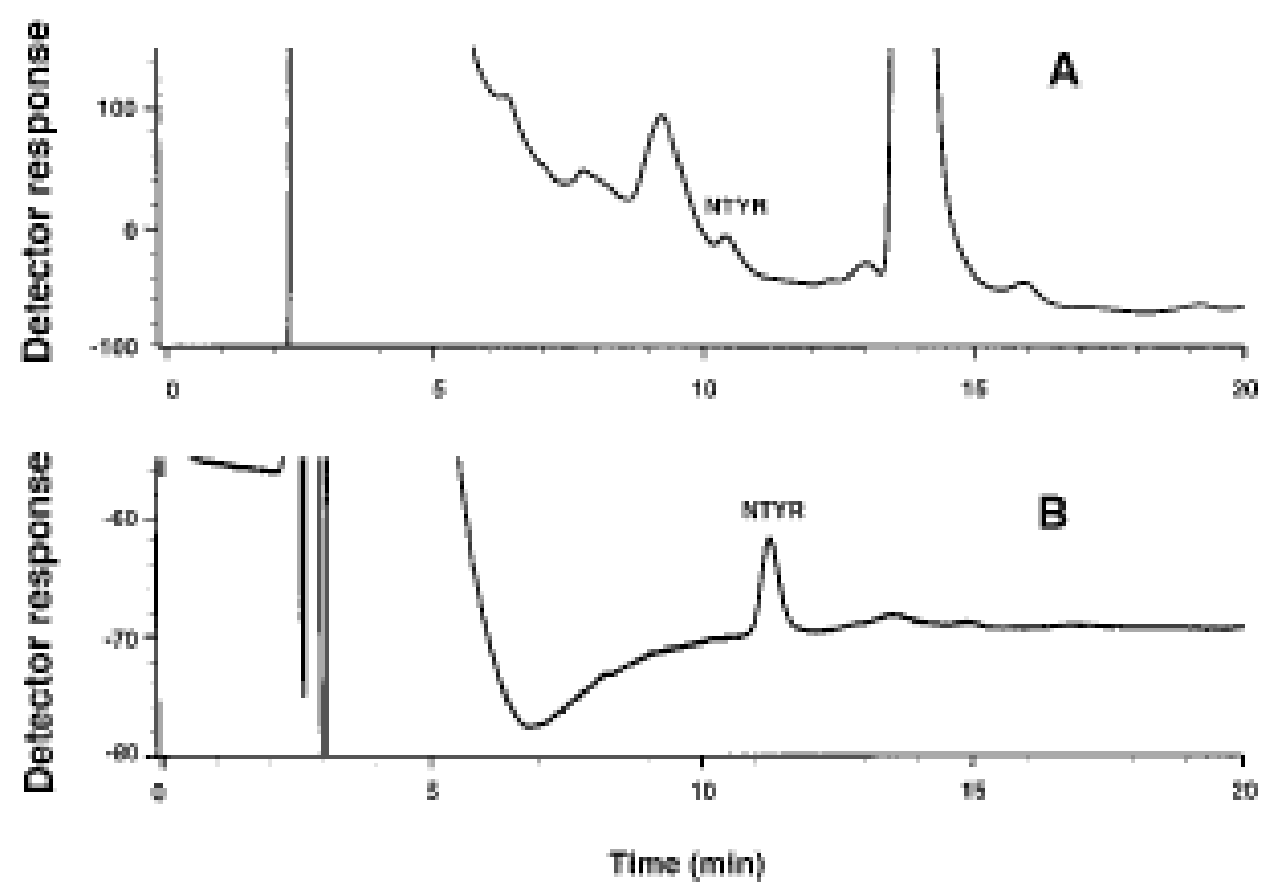

Figure 5. Typical chromatograms obtained from HPLC-ED analyses of NTYR in the absence (A) or presence (B) of the reduction column. The enzymatic hydrolyzate of peroxynitrite-treated BSA, which contained $0.03 \mathrm{mmol} / \mathrm{TYR} \mathrm{mmol}$, was analysed. When the reduction capacity decreased, the reduction column was activated by washing with distilled water, aqueous ascorbic acid $(0.1 \mathrm{M})$, and then distilled water for $15 \mathrm{~min}$ each at a flow rate of $0.5 \mathrm{ml} / \mathrm{min}$. H. Ohshima, I. Celan, L. Chazotte, B. Pignatelli, H.F. Mower, NITRIC OXIDE: Biology and Chemistry, 1999, 3, 2, 132-141 [38]. 
Using these parameters the authors were able to successfully determine hydrolytes of bovine serum. As shown in figure 5 without the reduction column, using the "detector" cell alone many peaks were reported to be evident in the chromatogram at both electrode 1 and 2, making the determination of 3-nitrotyrosine problematic. However, when using the "generator" electrode, a single well-defined peak for 3nitrotyrosine was obtained, free from any interference, and under these conditions detection limits of $5 \mathrm{nM}$ were reported for human serum for a sample volume of $1 \mathrm{ml}$ after a sample clean-up via purification with a $\mathrm{C}_{18}$ cartridge. This compares rather favourably, with that obtained by single LC-EC $(10 \mathrm{nM})$ and that by UV diode array $(50 \mathrm{nM})$ [39]. Recoveries for this study of $86.9 \pm 5.4 \%(\mathrm{n}=5)$ were reported for human plasma fortified at $10 \mu \mathrm{M}$.

Sodum et al. [40] have undertaken a similar study on the LC-DED determination of 3-nitrotyrosine (xviii). LC determination was undertaken using an UV diode array detector in series to the DED. The flow cell was equipped with glassy carbon and $\mathrm{Au} / \mathrm{Hg}$ electrodes in series, with the $\mathrm{Au} / \mathrm{Hg}$ electrode upstream and the glassy carbon electrode downstream. The LC system used for the analysis of 3-nitrotyrosine in biological samples consisted of two Ultrasphere ODS $3 \mu \mathrm{m}$ columns in series, each $150 \mathrm{~mm}$ x $4.6 \mathrm{~mm}$, and a Ultrasphere ODS $5 \mu \mathrm{m}$ guard column. The mobile consisted of $5 \%$ methanol, in $50 \mathrm{mM}$ sodium acetate, $\mathrm{pH} 4.7$, at a flow rate of $0.7 \mathrm{ml} / \mathrm{min}$. The applied potentials for each cell were identified by HDV, and the optimum conditions were found to be, $-0.9 \mathrm{~V}$ for the downstream electrode and $+0.6 \mathrm{~V}$ for the subsequent downstream electrode. The authors reported at the $\mathrm{Au} / \mathrm{Hg}$ amalgam electrode was superior to other materials such as GCE and Au for the reduction of 3-nitrotyrosine, producing a $25-40 \%$ increase in sensitivity other the other electrode materials investigated. Using the LC-DED method, a detection limit of $50 \mathrm{fM}$ was reported, 
and even in actual biological samples a detection limit of $<1 \mathrm{pM}$ was achieved. Only about $400 \mathrm{pM}$ could be determined using UV diode array detection.

\subsubsection{Vitamin $K$ and $Q_{10}$}<smiles>CC1=C(C/C=C(\C)CCCC(C)CCCC(C)CCCC(C)C)C(=O)c2ccccc2C1=O</smiles>

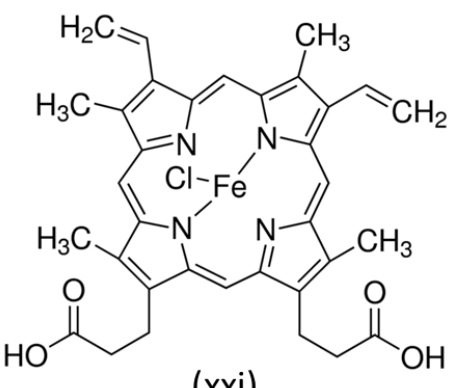

(xxi)

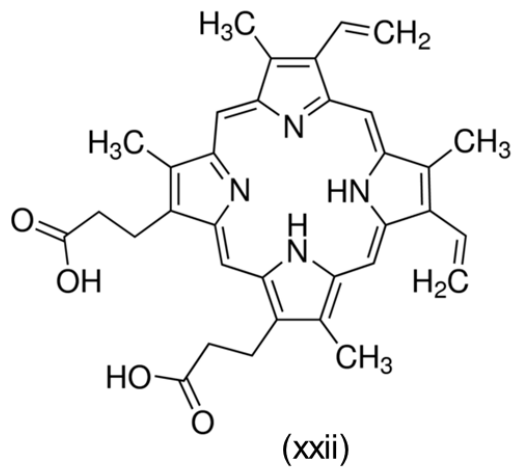<smiles>CCCCC1=C(C)C(=O)C(OC)=C(OC)C1=O</smiles>

$(x x)$<smiles>NC(=O)c1cccnc1</smiles>

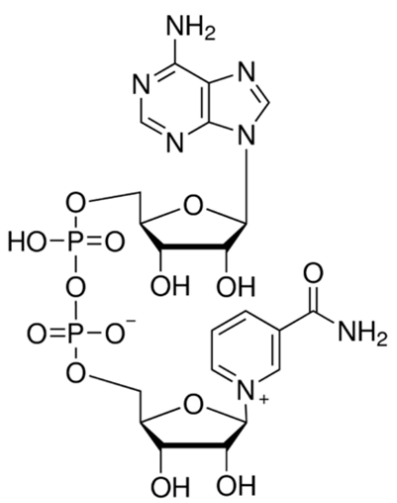<smiles>Cc1cc2nc3c(=O)[nH]c(=O)nc-3n(CC(O)[C@H](O)[C@H](O)CO)c2cc1C</smiles>

$(x x v)$<smiles>Cc1cc2nc3c(=O)[nH]c(=O)nc-3n(CC(O)[C@H](O)[C@H](O)COP(=O)(O)O[Na])c2cc1C</smiles>

(xxiv)

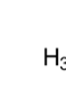

(xxvii)<smiles>Cc1cc2nc3c(=O)[nH]c(=O)nc-3n(CC(O)C(O)C(O)COP(=O)([O-])OP(=O)([O-])OCC3OC4C(O)C3OC4n3cnc4c(N)ncnc43)c2cc1C</smiles><smiles>COC1=C(OC)C(=O)C(C)=CC1=O</smiles>

(xxviii) 
Normal and subnormal circulating levels of phylloquinone (vitamin $\mathrm{K}_{1}$ ) (xix) with concentrations down to $20 \mathrm{pgml}^{-1}$ have been measured in plasma by LC-DED in the redox mode [41]. The sensitivity of the DED system was found to be at least an order of magnitude greater than that gained by LC-EC, operated in reductive mode at a single glassy carbon electrode and three times more sensitive than HPLC with UV detection. The porous graphite electrode generator and detector electrode potentials were set at $-1.3 \mathrm{~V}$ and $0 \mathrm{~V}$ respectively. Using a mobile phase of $95 \%$ methanol, 0.05 $\mathrm{M}$ acetate buffer, $\mathrm{pH} 3.0$ at a flow rate of $1.0 \mathrm{ml} / \mathrm{min}$ both normal circulating levels of phylloquinone $\left(\right.$ mean $\left.=376 \mathrm{pgml}^{-1}, \mathrm{n}=15\right)$ and sub-normal levels, seen inpatients suffering from osteoporosis (mean $=98 \mathrm{pgml}^{-1}, \mathrm{n}=16$ ) could be successfully measured after extraction with hexane and further purification via semi-preparative HPLC.

The coenzyme Q-10 (CoQ-10) (xx) has been the focus of scientific study for years and has become one of the most popular dietary supplements, and has been proposed, in the treatment of many conditions, including heart disease, hypertension, AIDS, asthma, Parkinson's and Huntington's disease, certain cancers, lung disease, gum disease, chronic fatigue syndrome, migraines, allergies and oxidative stress. CoQ-10 is also called ubiquinone, the name derived from the fact that it is a quinone that it is ubiquitous in living organisms. A number of studies by Tang et al. [42-44] have been made on the CoQ-10 using coulometric LC-DED. Venous blood samples were first extracted with 1-propanol and centrifuged; with the resulting supernatant was then examined by LC-DED. The optimal electrochemical conditions were identified by HDV. Studies were undertaken using an electrochemical conditioning cell and a $\mathrm{DED}$ in series. CoQ-10 was converted to the reduced form $\left(\mathrm{Q} 10 \mathrm{H}_{2}\right)$ electrochemically at $-0.65 \mathrm{~V}$ at the cell of the DED, and then re-oxidised to give the 
analytical signal at the subsequent cell at $+0.45 \mathrm{~V}$. For the analysis of total CoQ-10, the conditioning cell, place in-line before the analytical column was held at $+0.7 \mathrm{~V}$ to reduce any CoQ-10 to the reduce $\mathrm{Q} 10 \mathrm{H}_{2}$ form. The efficiency of the electrochemical conversion of $\mathrm{Q} 10$ to $\mathrm{Q} 10 \mathrm{H}_{2}$ was investigated, by comparing the peak heights of $\mathrm{Q}_{10 \mathrm{H}_{2}}$ and CoQ10 per injected amount of CoQ-10. This was studied over the concentration range $0.01 \mu \mathrm{gl}^{-1}$ to $4.0 \mu \mathrm{gl}^{-1}$, with conversion rates of $99.4 \pm 0.5 \%$ reported. The linear range for $\mathrm{Q}^{10 \mathrm{H}_{2}}$ and CoQ-10 using CoQ9, as an internal standard was obtained from $10 \mu \mathrm{gl}^{-1}$ to $4 \mathrm{mgl}^{-1}$ inter and intraday assay coefficients of variation were $<5 \%$ were reported over four concentration ratios of CoQ-10. The analytical column was a microsorb-mv column $(150 \mathrm{~mm} \times 4.6 \mathrm{~mm}, 5 \mu \mathrm{m})$ with a $\mathrm{C}_{18}$ guard column $(100 \mathrm{~mm} \times 4.6 \mathrm{~mm}, 5 \mu \mathrm{m})$. A mobile phase of $1.5 \%$ acetate buffer, $\mathrm{pH}$ 6, $1.5 \%$ 2-propanol, $69.5 \%$ methanol and $27.5 \%$ hexane, at a flow rate of 1.0 $\mathrm{ml} / \mathrm{min}$

Interference studies were made using the Dade ${ }^{\circledR}$ high control, which contained 45 drugs and endogenous substances, this was supplemented with a further 20 commonly prescribed drugs at concentrations exceeding relevant clinical values. The authors reported that none of these compounds produced any interference with any of the target analytes.

Interestingly, LC-DED in the redox mode has been used in investigations for the detection signs of life $[45,46]$. In theses studies, a broader definition of life has been postulated, based on the premise that for life to exist it requires an input of energy. This energy is tapped and controlled via transport through electron donors and acceptors along electron transport chains. These electron donors and acceptors are normally electrochemically reversible, or at least quasireversible in nature, and hence can be measured using dual electrode detection. Examples generally resemble 
prophyrins, quinones, flavins and nicotinamides. The detection of these compounds can be used as a method of detecting the presence of life. Crawford et al. [45] and Lang et al. [46] have made recent studies on the possibility of using LC-DED to detect these compounds, and potentially in use extraterrestrial environments. A set of representative molecules (haemin (xxi), haematin (as haemin, but with hydroxyl ligand instead of $\mathrm{Cl}$ ), Protoporphyrin IX (xxii), nicotinamide (xxiii), nicotinamideadenine dinucleotide (NAD) (xxiv), riboflavin (xxv), flavin mononucleotide (xxvi) and flavin adenine dinucleotide (FAD) (xxvii), 2,3-dimethoxy-5-methyl-1,4benzoquinone $\left(\mathrm{Q}_{0}\right)$ (xxviii) were investigated using LC-DED in series after UV diode array detection. Chromatographic separations were undertaken on either an amide $\mathrm{C}_{16}$ or a $\mathrm{C}_{18}$ reverse phase column $(150 \times 4.6 \mathrm{~mm}, 5 \mu \mathrm{m})$ using ion-paring gradient elution. The gradient was a two phase system, consisting of A: $5 \mathrm{mM}$

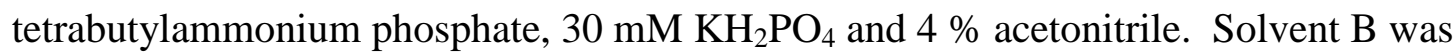
$100 \%$ acetonitrile. The gradient elution ran from 0 to $40 \% \mathrm{~B}$ at 35 minutes, than isocratic at this concentration for 5 minutes, followed by 5 minutes post-run wash of $100 \%$ A. LC-DED "generator" electrode was set to $-0.5 \mathrm{~V}$ and the "detector" electrode to $+1.0 \mathrm{~V}$. Supercritical fluid extracts of soil, sand and bacterial cultures were investigated and a number of the target analytes identified (nicotinamide, NAD, Riboflavin, FMN, and $\mathrm{Q}_{0}$ ), and designs were reported for possible miniaturisation of the LC-DED system.

\section{Conclusions}

A large proportion of the work reported in the past five years has focused on the Coulochem detector system, with little being reported on other detector designs. Work has generally focused on the use of LC-DED in screening mode, with only a few reports on either parallel dual electrode systems or procedures using redox mode 
detection. LC-DED has been shown in many cases to be both more sensitive and more selective than more commonly used detectors such as UV or mass spectroscopy. Interesting new developments such as miniaturisation of LC-DED has been reported $[45,47]$, and other separation techniques such as electrophoresis also regularly used with DED. It is envisage that in future studies that a large portion of reported work will continue with the use of the Coulochem detector, as this has been shown to be a popular chose. Outside of this, the combination of on-line electrochemistry and techniques such as mass spectroscopy (EC/MS) [48-50] are receiving a great deal of interest. They have been described as a rapid method for early-stage drug metabolite discovery and to anticipate biological oxidation patterns.

\section{Acknowledgements}

I would like to thank the Royal Society of Chemistry for inviting me to submit this chapter and also my fellow researchers whose work has been described in this review. 


\section{References}

[1] K. Štulik, V. Pacáková, Electroanalytical Measurements in Flowing Liquids, 1987, Ellis Horwood.

[2] R. Dawson, Jr, S.M. Messina, C. Stokes, S. Salyani, N. Alcalay, N.C. de Fiebre, C.M. de Fiebre, Toxicol. Mech. Meth. 2002, 12, 45-58.

[3] G.N. Mahoney, W. Al-Delaimy, J. Chromatogr. B Biomed. Sci. Appl. 2001, 753, 179-187.

[4] D.V. McCalley, Adv. Chromatogr. 2008, 46, 305-350.

[5] D.V. McCalley, J. Chromatogr. A 2010, 1217, 858.

[6] A.J. Alpert, J. Chromatograph. A, 1990, 499, 177-196.

[7] P. Hemström, K. Irgum, J. Sep. Sci. 2006, 29, 1784-1821.

[8] B. Buszewski, S. Noga, Anal. Bioanal. Chem. 2012, 402, 231-247.

[9] A. Kumar, J.P. Hart, D.V. McCalley, J. Chromatogr. A, 2011, 1218, 38543861.

[10] M. Trojanowicza, Anal. Chim. Acta, 2009, 653, 36-58.

[11] M. Trojanowicza, Anal. Chim. Acta, 2011, 688, 8-35.

[12] R.J. Flanagan, D. Perrett, R. Whelpton, Electrochemical Detection in HPLC Analysis of Drugs and Poisons. 2005, Royal Society of Chemistry.

[13] H.B. Hanekamp, P. Bos, R.W. Frel, TrAC, 1982, 1, 135-140.

[14] K. Štulík, V. Pacáková, Electroanalytical Measurements in Flowing Liquids. 1987, Ellis Horwood.

[15] P.T. Kissinger, Electrochemical Detection in Liquid Chromatography and Flow Injection Analysis, in P.T. Kissinger, W.R. Heineman (ed.) Laboratory Techniques in Electroanalytical Chemistry, Marcel Dekker, New York, 1984 p. 611-635.

[16] D.C. Johnson, W.R. LaCourse, Anal. Chem. 1990, 62, 589A-597A

[17] W.J. Blaedel, L.N. Klatt, Anal. Chem. 1966, 38, 879-883.

[18] J. Yamada, J. Electroanal. Chem. 1973, 44, 189-198.

[19] S.G. Weber, W.C. Purdy, Anal. Chim Acta, 1979, 102, 41-59.

[20] J. Yamada, H. Matsuda, J. Electroanal. Chem. 1973, 44, 189-198.

[21] K.C. Honeychurch, J.P. Hart, Electroanalysis, 2007, 19, 2176-2184.

[22] C.E. Lunte, P.T. Kissinger, Anal. Chem. 1983, 55, 1458-1462.

[23] L.B. Anderson, C.N. Reilly, J. Electroanal. Chem. 1965, 10, 295-305.

[24] S.A. McClintock, W.C. Purdy, Anal. Lett. 1981, 14, 791-798.

[25] S.A. McClintock, W.C. Purdy, Anal. Chim. Acta, 1983, 148, 127-133.

[26] R.J. Fen, S.Sigga, D.J. Curran, Anal. Chem. 1978, 50, 1067-1073.

[27] I.N. Acworth, M. Bowers, An Introduction to HPLC-Based Electrochemical Detection: From Single Electrode to Multi-Electrode Arrays. In: Coulometric Electrode Array Detectors for HPLC. Progress in HPLC-HPCE. 6. Acworth, I. N., Naoi, M., Parvez, S., and Parvez, H. (Eds.). 1997, VSP Publications, The Netherlands. p. 3-50.

[28] C.N. Svendsen, Analyst, 1993, 118, 123-129.

[29] I.N. Acworth, P. Gamache, American Lab. 1996, 5, 33-38.

[30] I.N. Acworth, J. Waraska, P. Gamache, American Lab. 1997, 11, 25-32.

[31] M. Goto, J. Liq. Chromatogr. 1983, 6, 1907-1925.

[32] K.C. Honeychurch, G.C. Smith, J.P. Hart, Anal. Chem. 2006, 78, 416-423.

[33] K.C. Honeychurch, J.P. Hart, J. Solid State Electr. 2008, 12, 1317-1324. 
[34] K.C. Honeychurch, A.T. Chong, K. Elamin, J.P. Hart, Anal. Methods, 2012, 4, 132-140.

[35] D.M. Radzik, J.S. Brodbelt, P.T. Kissinger, Anal. Chem. 1984, 56, 2927-2931.

[36] K.R. Rogers, J.Y. Becker, J. Wang, F. Lu, Field Anal. Chem. Tech. 1999, 3, 161-169.

[37] K.R. Rogers, J.Y. Becker, J. Cembrano, Electrochim. Acta, 2000, 45, 43734379.

[38] H. Ohshima, I. Celan, L. Chazotte, B. Pignatelli, H.F. Mower, Nitric OxideBiol. Ch., 1999, 3, 2, 132-141.

[39] H. Kaur, L. Lyras, P. Jenner, B. Halliwell, J. Neurochem., 1998, 70, 5, 22202223.

[40] R.S. Sodum, S.A. Akerkar, E.S. Fiala, Anal. Biochem. 2000, 280, 278-285.

[41] J.P. Hart, M.J. Shearer, P.T. McCarthy, Analyst, 1985, 110, 1181-1184.

[42] P.H. Tang, M.V. Miles, P. Steele, A. DeGrauw, G. Chuck, L. Schroer, A. Pesce, Clin. Chim. Acta, 2002, 318, 127-131.

[43] P.H. Tang, M.V. Miles, L. Miles, J. Quinlan, B. Wong, A. Wenisch, K. Bove, Clin. Chim. Acta 2004, 341, 173-184.

[44] P.H. Tang, M.V. Miles, A. DeGrauw, A. Hershey, A. Pesce, Clin. Chem. 2001, 47, 2, 256-265.

[45] R.L. Crawford, A. Paszczynski, Q. Lang, I.F. Cheng, B. Barnes, T.J. Anderson, R. Wells, C. Wai, G. Corti, L. Allenbach, D.P. Erwin, J. Park, T. Assefi, M. Mojarradi, Icarus, 2001, 154, 531-539.

[46] Q. Lang, I.F. Cheng, C.M. Wai, A. Paszczynski, R.L. Crawford, B. Barnes, T.J. Anderson, R. Wells, G. Corti, L. Allenbach, D.P. Erwin, T. Assefi, M. Mojarradi, Anal. Biochem., 2002, 301, 225-234.

[47] E. Sahlin, A. ter Halle, K. Schaefer, J. Horn, M. Then, S.G. Weber, Anal. Chem. 2003, 75, 1031-1036.

[48] A. Baumann, W. Lohmann, B. Schubert, H. Oberacher, U. Karst, J. Chromatogr. A, 2009, 1216, 3192-3198.

[49] A. Mouithys-Mickalad, J.-M. Kauffmann, C. Petit, J. Bruhwyler, Y. Liao, H. Wikstrom, J. Damas, J. Delarge, G. Deby-Dupont, J. Geczy, J.-F. Liegeois, J. Med. Chem. 2001, 44, 769-776.

[50] S.M. van Leeuwen, B. Blankert, J.-M. Kauffmann U. Karst, Anal. Bioanal. Chem. 2005, 382, 742-750. 